\title{
Influência do estado nutricional materno e ganho de peso na gestação sobre o desfecho fetal
}

Bruna de S. Lima*, Ana Paula V. Sanches, Josilene L. de Oliveira, Laís A.P.Simino, Marcio A. Torsoni, Marciane Milanski, Adriana S. Torsoni e Leticia M. Ignacio-Souza.

\section{Resumo}

Segundo a OMS, a obesidade é o acúmulo de gordura anormal ou excessiva no organismo acarretando o comprometimento da saúde. No caso da saúde das mulheres, tem sido associada a efeitos adversos a curto e longo prazos, podendo apresentar diminuição da capacidade reprodutiva e aumento do risco de desfechos adversos na gestação. Portanto, o estudo das interações entre o ambiente materno e fetal, poderá elucidar mecanismos e pontos chave no tempo e no desenvolvimento onde as intervenções médico-nutricionais possam ser mais eficazes.

Palavras-chave: obesidade, prenhez, programação metabólica

\section{Introdução}

A obesidade, no caso da saúde das mulheres, tem sido associada a efeitos adversos a curto e longo prazos, podendo impactar de modo significativo o ambiente intrauterino e, portanto, no desenvolvimento fetal e na saúde da criança no curso da vida. Dessa forma, o estado nutricional da mãe, envolvendo fatores como composição corporal, ingestão dietética, ambiente intra-uterino e desenvolvimento feto-placentário, afeta não só as adaptações metabólicas maternas à gestação, como também poderia programar o feto.

\section{Resultados e Discussão}

O excesso de peso do grupo HFD foi determinado pela maior ingestão diária em Kcal $(p<0,05)$ e levou a alterações no GTT, prejudicando o metabolismo de glicose no momento imediatamente anterior à gestação.
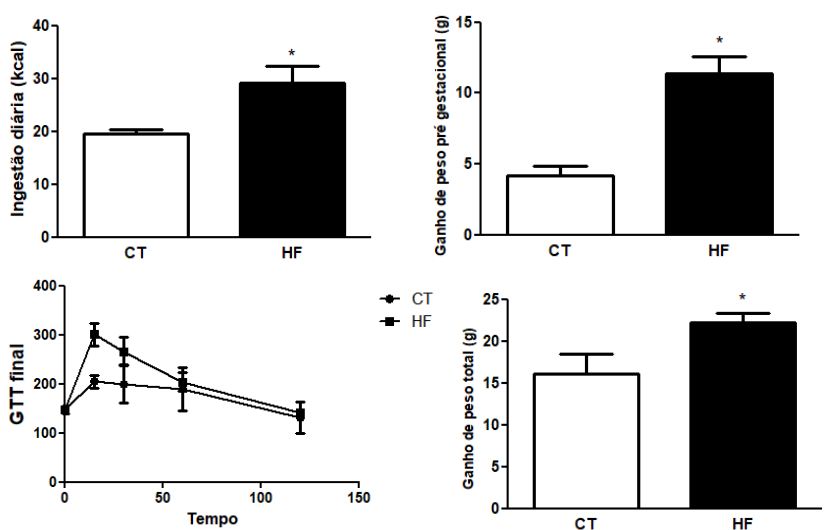

Figura 1. Ingestão diária em $\mathrm{Kcal}$, ganho de peso prégestacional, GTT final e ganho de peso total.

Quanto ao ganho de peso pré-gestacional, peso materno e peso placentário, assim como a relação com a área da placenta, foi observada correlação negativa, sendo, portanto, inversamente proporcionais, sugerindo assim, prejuízo no desenvolvimento. Isso pode ser justificado pelo aumento de citocinas inflamatórias que ocorrem naturalmente na obesidade materna, sugerindo um quadro de insuficiência placentária e diminuição de transporte de nutrientes, gerando assim bebês pequenos para idade gestacional devido ao retardo de crescimento uterino.
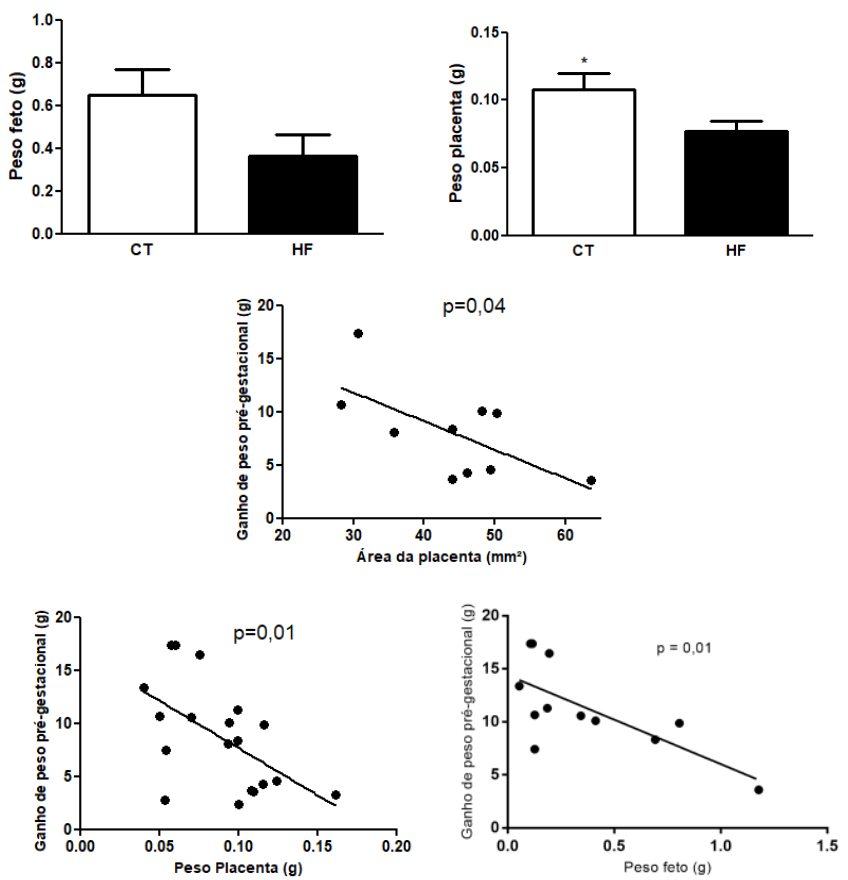

Figura 2. Peso fetal e placentário (grupo CT e HF), correlação entre ganho de peso pré-gestacional e área da placenta (grupo HF), peso da placenta (grupo CT e HF) e peso fetal (grupo HF).

\section{Conclusões}

O ganho de peso pré-gestacional excessivo prejudicou as adaptações maternas à gestação e modulou o crescimento placentário e fetal de maneira inversa, sugerindo prejuízo no desfecho de saúde para a prole a curto e, possivelmente, a longo prazo.

\section{Agradecimentos}

FAEPEX, CNPq, FAPESP, CAPES

WORLD HEALTH ORGANIZATION. Obesity and overweight. WHO, 2017.

WIXEY, J.A. Review: Neuroinflammation in intrauterine growth restriction. ELSEVIER, Australia, v.54, p.117-124, 2017 